\title{
Effect of Slot Array at Different Angles towards the Performance of Hollow Pyramidal Microwave Absorber
}

\author{
Mas Izzati Fazin ${ }^{1}$, Hasnain Abdullah@Idris ${ }^{2}$, Ahmad Rashidy Razali ${ }^{3}$, Mohd Nasir Taib ${ }^{4}$, \\ Norhayati Mohamad Noor ${ }^{5}$ \\ ${ }^{1}$ Faculty of Electrical Engineering, Universiti Teknologi MARA, Cawangan Pulau Pinang, Malaysia, \\ mas.ezaty.me@gmail.com \\ ${ }^{2}$ Faculty of Electrical Engineering, Universiti Teknologi MARA, Cawangan Pulau Pinang, Malaysia, \\ hasnain@uitm.edu.my \\ ${ }^{3}$ Faculty of Electrical Engineering, Universiti Teknologi MARA, Cawangan Pulau Pinang, Malaysia, \\ ahmad073@uitm.edu.my \\ ${ }^{4}$ Faculty of Electrical Engineering, Universiti Teknologi MARA, Shah Alam, Selangor, Malaysia, \\ dr.nasir@ieee.org \\ ${ }^{5}$ Faculty of Electrical Engineering, Universiti Teknologi MARA, Cawangan Pulau Pinang, Malaysia, \\ hayati005@uitm.edu.my
}

\begin{abstract}
This paper presents the performance of electromagnetic wave absorption at different angles with novel slot array design implemented on hollow pyramidal microwave absorber. The size of pyramidal shaped absorber is selected to comply with the industrial standard and can operate at the frequency range between $1 \mathrm{GHz}$ to $12 \mathrm{GHz}$. Initially, six designs slot array on hollow pyramidal microwave absorber are fabricated using biomass carbon. Their electromagnetic wave absorption at $0^{\circ}$, $30^{\circ}$ and $60^{\circ}$ angles are measured to analyze their performance. The performance results show that the absorption rates are sensitive to angle of measurement. The observation shows that the designs of slot array at S, C and X frequency bands give better absorption performance of up to $60^{\circ}$. The overall results for all slot array design at different angles are analyzed and compared.
\end{abstract}

Key words: Slot array, microwave absorber, absorption performance, electromagnetic wave

\section{INTRODUCTION}

Microwave absorber is an important element in Anechoic Chamber. An RF Anechoic Chamber is a protected room whose walls have been secured with Microwave Absorber that absorb such an extensive amount of the undesirable signal [1]. Electromagnetic wave absorbers and anechoic chamber are used throughout the world in performing antenna and reflectivity measurements [2]. The creation of non-reflection room is required to remove all the unwanted signal from interrupting the system operation. Most of the absorbers are working in broad frequency range and typically made from blocks of absorbing materials and used for interferes with the reflection of the electromagnetic waves passing through the absorber [3].

Some researchers have mentioned that carbon has a significant function in microwave absorption [4], [5]. Carbon is an excellent microwave absorber as it is easily heated by microwave energy. Carbon is ideal for converting microwave energy into thermal energy because signal is blocked when they pass through carbon [6], [7]. A proper RF absorber models are developed based on information, for instances absorbers reflectivity and reflection coefficient [8][9]. The permittivity, permeability and the frequency of the material can control the reflectivity, R. The reflectivity can be expressed in $\mathrm{dB}$ unit as following the equation (1) below.

$$
R=20 \log |\Gamma|
$$

In broadcast communications, the proportion of the amplitude of the reflected wave to the amplitude of the incidence wave is considered as reflection coefficient. The reflection coefficient, $\Gamma$ can be defined as the following equation (2) below.

$$
\Gamma=\frac{\mathrm{Zl}-1}{\mathrm{Zi}+1}
$$

Dielectric constant is equivalent to relative permittivity $(\varepsilon r)$ or the absolute permittivity $(\mathcal{E})$ comparative with the permittivity of free space $\left(\varepsilon_{0}\right)$ [9], [10]. The dielectric constant of a material influences on electromagnetic signals travel through the material. If the dielectric constant has a high value, it can make the signal such as radio waves or light travel more gradually [11], [12]. Further improvement of the absorber reflectivity is possible by implementing the slot array technique in antenna design on the hollow pyramidal 
microwave absorbers. Commonly, slots are popular among antenna technology to increase the gain, bandwidth, RFID and multiband applications. [13]-[16]. This has encouraged the researchers to identify and research the design of the slot array antenna implementation on the hollow pyramidal absorber[17]-[19]. In this paper, slot array is invented to the hollow pyramidal microwave absorbers. The study involve analyzing the reflectivity performances based on measurement angles and the frequency bands. This study is important to determine the relationship between slot array patterns effecting the performance at different angle of wave incident.

\section{STRUCTURE OF PYRAMIDAL ABSORBER}

The reflectivity is an important parameter of radiation absorbing material (RAM). Absorption performance is the result from many reflections that take place between the pyramids. Because a single pyramid is relatively large compared to wavelengths, the sides of the pyramid usually reflect incident wave. Thus, some part of the wave can cause a lot of reflection before it gets to the solid absorption base, and the remaining waves are then reflected. The reflectivity performance is determine by comparing the magnitude of the reflection with the magnitude of the incident waveform, where the absorber is considered an infinite plane [20]. Figure 1 below shows the comparison design of commercial absorber and slotted absorber.

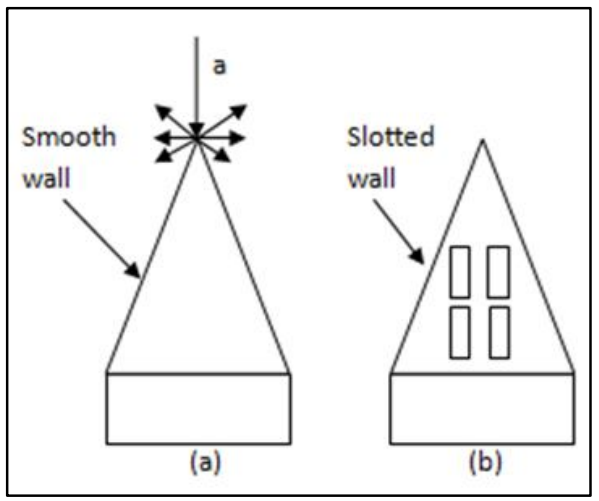

Figure 1: Side view profile of (a) commercial absorber (b) slotted absorber

The pyramidal absorber produce poor reflectivity performance when pyramid length is less than a quarter wavelength, $\lambda / 4$. The absorber would scatter just a restricted sum of energy of the incidence wave [20]. The incident energy at low and excessive top frequencies are in general attenuated with the aid of using $\lambda / 4$ resonances, corresponding to the wavelength of $\lambda / 4$ and $3 \lambda / 4$ separately. In evaluation to flat absorber, pyramidal shape obtain more interdependent results for broadband absorption. Furthermore, the pyramid kept up its absorption bandwidth in a wide incident angle, $50^{\circ}$ for transverse electric (TE) polarization and $60^{\circ}$ for transverse magnetic (TM) polarization has been reported in [21]. The impedance mismatching contributes to the bad absorption performance

In this study, the slotted array design technique is applied on the hollow pyramidal microwave absorbers in order to diminish dissipating from the tips and edges of pyramid. The creation of slotted array design is to improve the impedance matching as well as the absorber performance at what has been proven in slotted array antenna designs. Generally, it is necessary to study the absorption required for an application depends on the specification at the test facility. For example, the absorption required to achieve the performance of a particular space varies by size and shape of its protected shields. Therefore, the designed absorbers applied are similar with the conventional absorbers in terms of size and shape to satisfy the reflectivity criteria in the chamber. Figure 2 below shows the dimension of hollow pyramidal absorber from side view and top view.

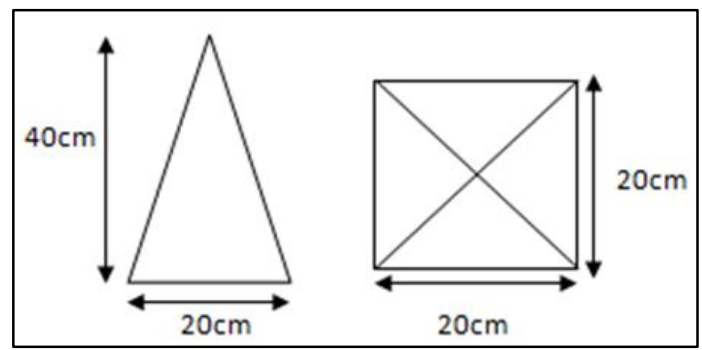

Figure 2: The dimensions of pyramidal absorber from frequency between $1 \mathrm{GHz}$ to $12 \mathrm{GHz}$ from side view and top view

\section{ABSORBER MEASUREMENT}

The initial proposed design and investigation of this study are simulated by using CST Microwave Studio. Then, the slotted array design of pyramidal absorber is fabricated and measured under free space arch to experimentally obtain the performance. Prior to the experimental design, the resistivity must be considered to ensure that the material is in a semiconductor state. In order to achieve the best result, the value of resistivity must be closed to $1 \mathrm{M} \Omega$ [18]. This is the value to obtain semiconductor material.

After obtaining the appropriate resistivity value, the measurement technique starts by placing a metal plate on the middle point of the arch to measure the reflection. The loss electromagnetic wave propagation is a feature indicates that the portion of energy loss in the propagation path. The propagation path is the way which electromagnetic waves move, ranging from the transmitter to the receiver [22]. The horn antenna is placed at a normal incident, $0^{\circ}$ of microwave absorber as shown in this paper [23]. Next step, the sample of absorber is place on the metal plate, and the reflection is measured. The same process is repeated again for $30^{\circ}$ and $60^{\circ}$. The reflection coefficient is define when the proportion of the sample reflection to the metal plate reflection [5]. 
Mas Izzati Fazin et al., International Journal of Emerging Trends in Engineering Research, 8(9), September 2020, 6306 - 6312

When the incidence and reflected electrical field, Ei and Er, and magnetic waves $\mathrm{Hi}$ and $\mathrm{Hr}$ enter vertically to the incident plane at random angle, $\theta \mathrm{i}$, in the reflection plane, the propagation constant, $\gamma$ can be characterized as the equation 3 following below.

$$
\gamma=\sqrt{j w \mu(\sigma+j w \epsilon)} \approx \sqrt{j w \mu \alpha}
$$

\section{RESULT AND DISCUSSION}

\section{A. Comparison of Non-Slot and Single Slot on Hollow} Pyramidal Absorber

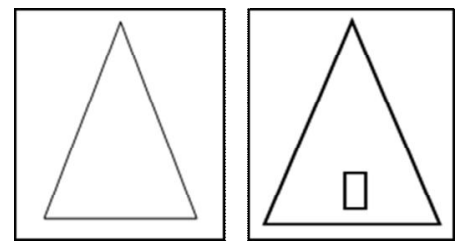

Figure 3: Non-slot and single slot on hollow pyramidal absorber

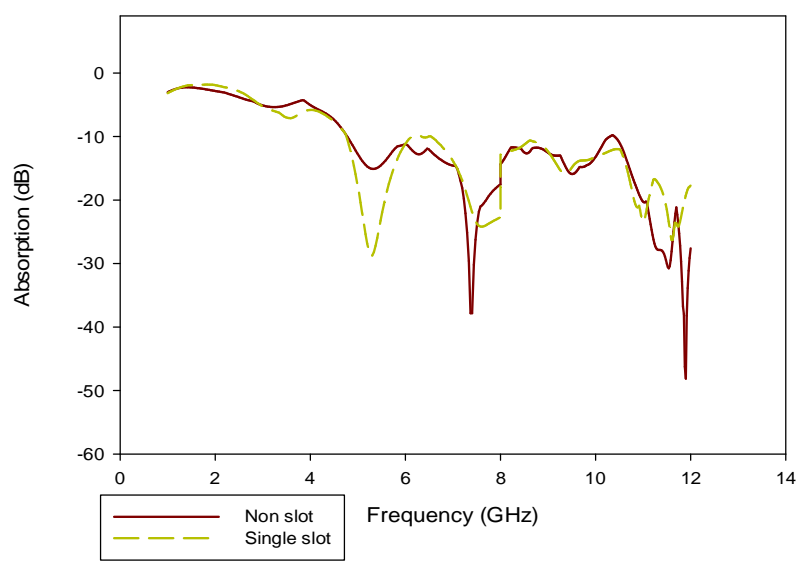

Figure 4: The absorption performance between non-slot and single slot at $0^{\circ}$

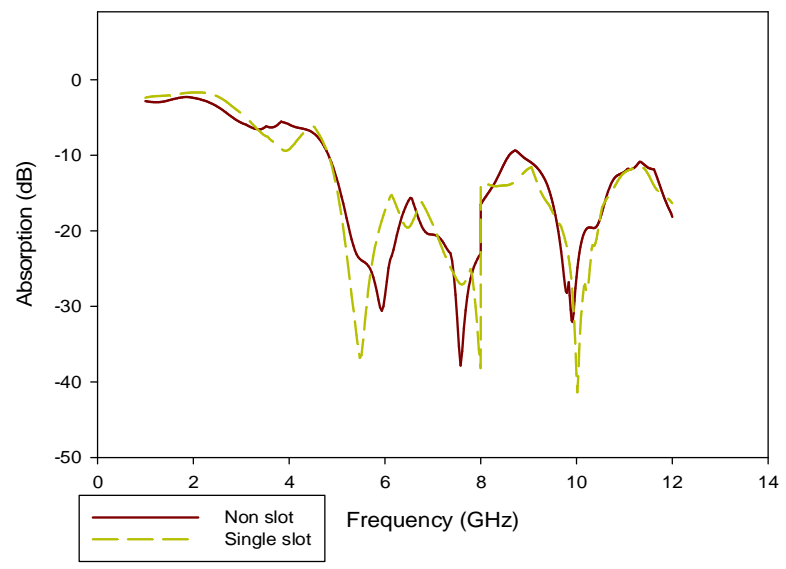

Figure 5: The absorption performance between non-slot and single slot at $30^{\circ}$

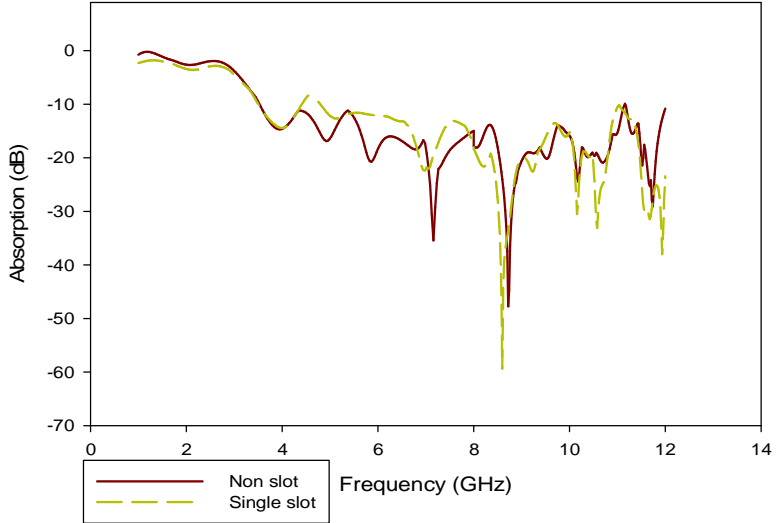

Figure 6: The absorption performance between non-slot and single slot at $60^{\circ}$

Figure 3 shows the design of non-slot and single slot on hollow pyramidal microwave absorber. The results are taken at $0^{\circ}, 30^{\circ}$ and $60^{\circ}$ as shown in Figure 4, 5 and 6. Both designs are compared to each other to analyze the significant absorption performance different throughout the frequency bands.

\section{B. Comparison of Two Array Slots (Model A) and (Model B) on Hollow Pyramidal Absorber}
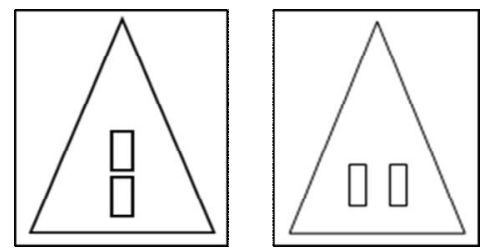

Figure 7: Two array slots (Model A) and (Model B) on hollow pyramidal absorber

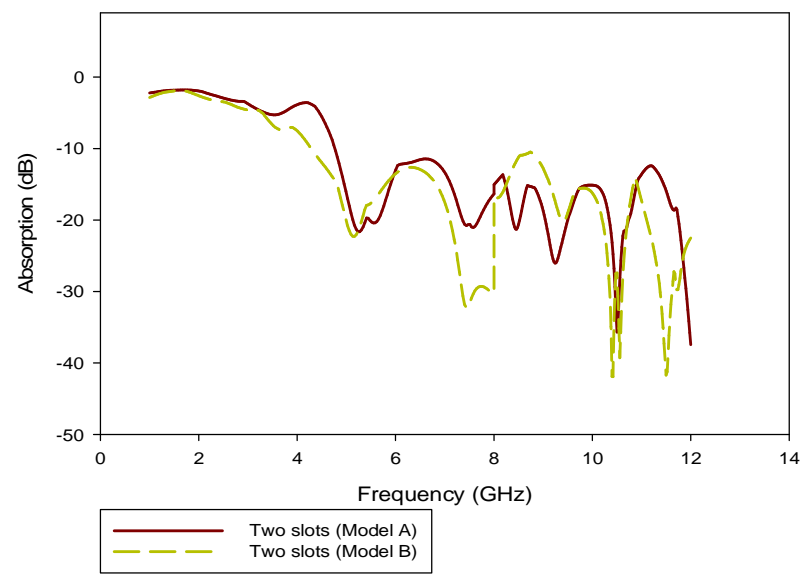

Figure 8: The absorption performance of two slots array (Model A) and (Model B) at $0^{\circ}$ 


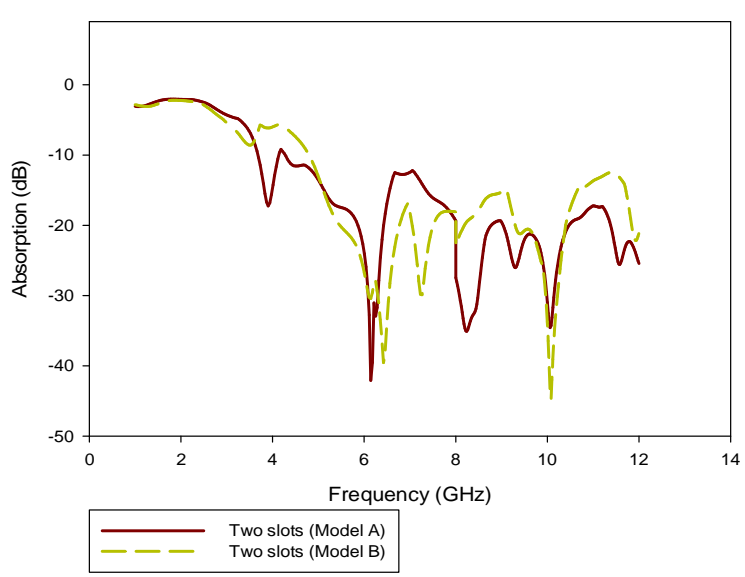

Figure 9: The absorption performance of two slots array (Model A) and (Model B) at $30^{\circ}$

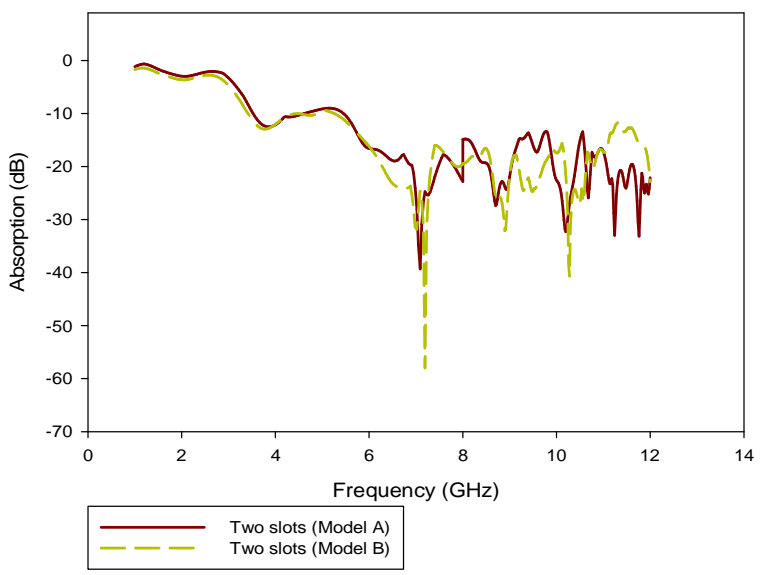

Figure 10: The absorption performance of two slots array (Model A) and (Model B) at $60^{\circ}$

Figure 7 shows the design of two different slots array on hollow pyramidal microwave absorber. The results are taken at $0^{\circ}, 30^{\circ}$ and $60^{\circ}$ as shown in Figure 8, 9 and 10. Both slots array designs are compared to each other to analyze the significant absorption performance different throughout the frequency bands.

C. Comparison of Four Array Slots (Model C) and (Model D) on Hollow Pyramidal Absorber
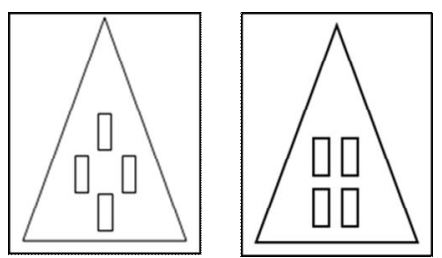

Figure 11: Four slots array (Model C) and (Model D)

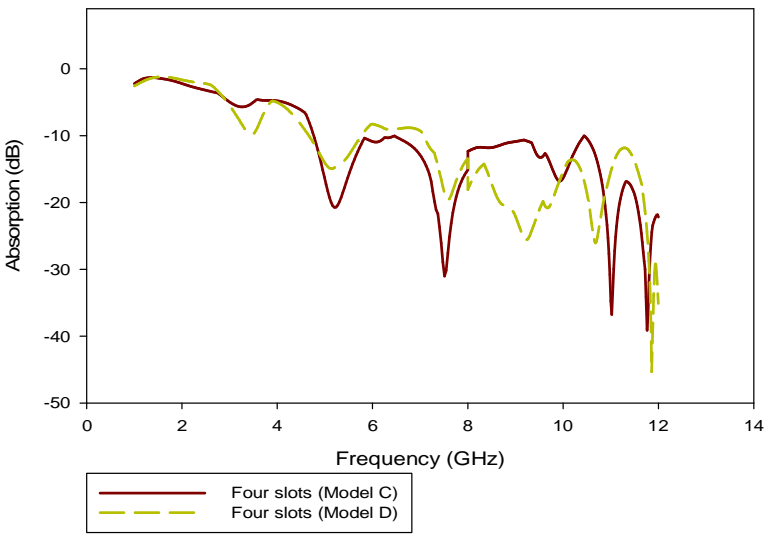

Figure 12: The absorption performance of four slots array (Model C) and (Model D) at $0^{\circ}$

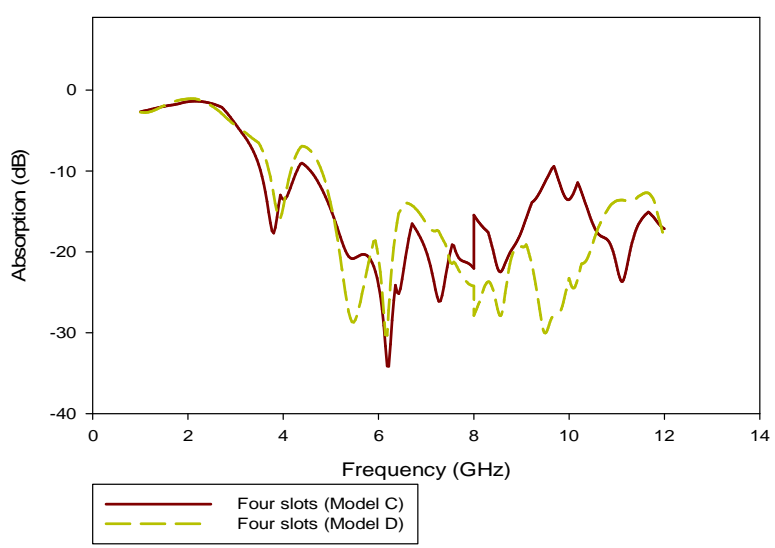

Figure 13: The absorption performance of four slots array (Model C) and (Model D) at $30^{\circ}$

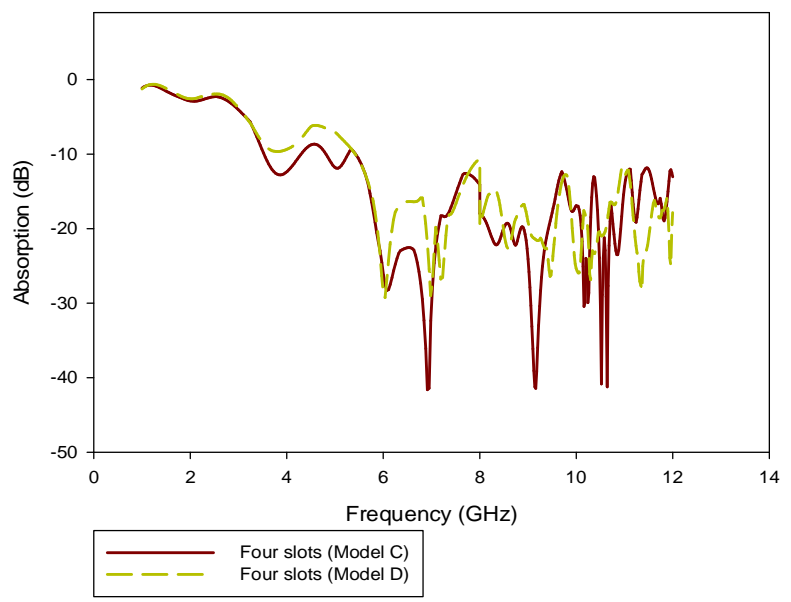

Figure 14: The absorption performance of four slots array (Model C) and (Model D) at $60^{\circ}$ 
Figure 11 shows the design of four slots array at different pattern on hollow pyramidal microwave absorber. The results are taken at $0^{\circ}, 30^{\circ}$ and $60^{\circ}$ as shown in Figure 12,13 and 14 . Both slots array designs are compared to each other to analyze the significant absorption performance different throughout the frequency bands.

Table 1: Minimum and maximum absorption performance of slots design at $0^{\circ}$

\begin{tabular}{|c|c|c|c|c|c|c|c|c|c|}
\hline \multirow{2}{*}{ Design } & \multirow{2}{*}{$\begin{array}{c}\begin{array}{c}\text { Frequency } \\
(\mathrm{GHz})\end{array} \\
\begin{array}{c}\text { Reflectivity } \\
(\mathrm{dB})\end{array}\end{array}$} & \multicolumn{2}{|c|}{$L$ band (1-2) } & \multicolumn{2}{|c|}{$S$ band (2-4) } & \multicolumn{2}{|c|}{$C$ band (4-8) } & \multicolumn{2}{|c|}{$X$ band (8-12) } \\
\hline & & Min & Max & Min & Max & Min & Max & Min & Max \\
\hline \multicolumn{2}{|c|}{ Non-Slot } & -1.17 & -2.96 & -3.99 & -5.27 & -10.91 & -38.37 & -9.11 & -47.61 \\
\hline \multicolumn{2}{|c|}{ Single Slot } & -1.83 & -3.27 & -1.93 & -7.08 & -5.84 & -28.89 & -10.88 & -26.32 \\
\hline \multicolumn{2}{|c|}{ Two Slots (Model A) } & -1.52 & -2.25 & -1.08 & -3.28 & -11.51 & -21.65 & -12.39 & -37.09 \\
\hline \multicolumn{2}{|c|}{ Two Slots (Model B) } & -1.88 & -2.32 & -4.08 & -7.82 & -12.86 & -32.18 & -10.45 & -42.04 \\
\hline \multicolumn{2}{|c|}{ Four Slots (Model C) } & -1.01 & -2.54 & -4.08 & -5.61 & -9.79 & -31.08 & -10.01 & -38.97 \\
\hline \multicolumn{2}{|c|}{ Four Slots (Model D) } & -0.50 & -1.72 & -2.93 & -10.21 & -5.02 & -19.94 & -11.96 & -45.43 \\
\hline
\end{tabular}

Table 2: Minimum and maximum absorption performance of slots design at $30^{\circ}$

\begin{tabular}{|c|c|c|c|c|c|c|c|c|c|}
\hline \multirow{2}{*}{ Design } & \multirow{2}{*}{$\begin{array}{c}\begin{array}{c}\text { Frequency } \\
\text { (GHz) }\end{array} \\
\begin{array}{c}\text { Reflectivity } \\
\text { (dB) }\end{array}\end{array}$} & \multicolumn{2}{|c|}{$L$ band (1-2) } & \multicolumn{2}{|c|}{$S$ band (2-4) } & \multicolumn{2}{|c|}{$C$ band (4-8) } & \multicolumn{2}{|c|}{$\mathrm{X}$ band (8-12) } \\
\hline & & Min & $\operatorname{Max}$ & Min & Max & Min & Max & Min & Max \\
\hline \multicolumn{2}{|c|}{ Non-Slot } & -2.32 & -3.20 & -2.10 & -6.72 & -5.83 & -37.44 & -9.13 & -32.18 \\
\hline \multicolumn{2}{|c|}{ Single Slot } & -1.45 & -1.88 & -1.67 & -9.35 & -15.27 & -37.66 & -11.54 & -41.38 \\
\hline \multicolumn{2}{|c|}{ Two Slots (Model A) } & -1.88 & -2.98 & -2.10 & -17.24 & -9.35 & -41.82 & -17.24 & -34.81 \\
\hline \multicolumn{2}{|c|}{ Two Slots (Model B) } & -1.88 & -2.98 & -5.83 & -8.91 & -17.24 & -39.41 & -12.64 & -44.69 \\
\hline \multicolumn{2}{|c|}{ Four Slots (Model C) } & -1.86 & -2.22 & -2.04 & -17.72 & -9.15 & -33.93 & -9.52 & -23.73 \\
\hline \multicolumn{2}{|c|}{ Four Slots (Model D) } & -1.13 & -2.59 & -2.41 & -14.99 & -6.97 & -30.29 & -12.61 & -30.29 \\
\hline
\end{tabular}

Table 3: Minimum and maximum absorption performance of slots design at $60^{\circ}$

\begin{tabular}{|c|c|c|c|c|c|c|c|c|c|}
\hline \multirow{2}{*}{ Design } & \multirow{2}{*}{$\begin{array}{c}\begin{array}{c}\text { Frequency } \\
\text { (GHz) }\end{array} \\
\begin{array}{c}\text { Reflectivity } \\
\text { (dB) }\end{array} \\
\end{array}$} & \multicolumn{2}{|c|}{$L$ band (1-2) } & \multicolumn{2}{|c|}{$S$ band (2-4) } & \multicolumn{2}{|c|}{$\mathrm{C}$ band (4-8) } & \multicolumn{2}{|c|}{$X$ band (8-12) } \\
\hline & & Min & Max & Min & Max & Min & Max & Min & Max \\
\hline \multicolumn{2}{|c|}{ Non-Slot } & -0.29 & -1.76 & -2.62 & -11.05 & -11.15 & -35.26 & -9.98 & -46.72 \\
\hline \multicolumn{2}{|c|}{ Single Slot } & -1.46 & -3.52 & -2.64 & -13.60 & -8.51 & -21.67 & -11.55 & -59.34 \\
\hline \multicolumn{2}{|c|}{ Two Slots (Model A) } & -1.17 & -2.64 & -2.35 & -12.05 & -8.80 & -39.07 & -13.52 & -33.20 \\
\hline \multicolumn{2}{|c|}{ Two Slots (Model B) } & -1.76 & -3.52 & -2.64 & -12.64 & -8.80 & -57.29 & -12.35 & -40.83 \\
\hline \multicolumn{2}{|c|}{ Four Slots (Model C) } & -0.79 & -2.54 & -2.10 & -13.08 & -8.48 & -28.65 & -12.64 & -41.38 \\
\hline \multicolumn{2}{|c|}{ Four Slots (Model D) } & -0.35 & -2.32 & -1.88 & -9.57 & -6.05 & -41.60 & -12.86 & -28.00 \\
\hline
\end{tabular}

In the literatures, there are researchers stated that the slot radial array was found to be one of the method to improve the reflectivity performance [18]. Therefore, it is expected that a single slot design should offered better performance than non-slot design on hollow pyramidal absorber. In the measurement of this study, the comparison between single slot design and non-slot design has been analyzed as in Table 1,2 , and 3 at $0^{\circ}, 30^{\circ}$ and $60^{\circ}$. At $0^{\circ}$, the results show that the single slot design have slightly better performance than non-slot design at low frequency band of L-band and S-band. At $\mathrm{C}$ and $\mathrm{X}$ frequency band, non-slot design however achieved better absorption than single slot design. Meanwhile, at measurement angle of $30^{\circ}$ and $60^{\circ}$, a single slot and non-slot design have slight difference in absorption performance at all bands. However, in average, the specific performance indicated that a single slot design obtain better absorption than non-slot design at frequency band of $\mathrm{C}$ and $\mathrm{X}$ frequency band. This result indicates that single slot design is capable to improve the absorption performance of a microwave absorber.

On the other hand, it is apparent from Table 1, 2 and 3, the performance between two slots array design in Model A and Model B shows that there is an improvement in term of absorption when compared to single or non-slot designs. At $0^{\circ}, 30^{\circ}$ and $60^{\circ}$, it is observed that the absorption performance between two slots array of Model A and Model B at L band has uncorrelated differences. However, Model B achieved an averagely better absorption performance compared to Model $\mathrm{A}$ at $\mathrm{S}, \mathrm{C}$ and $\mathrm{X}$ frequency band. In addition, the result shows that the angle of incidents on slot array design is sensitive to the reflectivity behavior, thus become an important role to be analyzed further to achieve better performance.

On top of that, Table 1,2 and 3 show that there is an uncorrelated difference between the four slots array designs (Model C) and (Model D) at L low frequency band at $0^{\circ}, 30^{\circ}$ and $60^{\circ}$. However, specific observation shows that at $0^{\circ}$, four 
slots array design (Model C) obtained better absorption performance than four slots array design (Model D) at $\mathrm{S}$ frequency band. Meanwhile, at X-band, Model D obtained better absorption performance than Model C. Apart from that, at $30^{\circ}$, Model $\mathrm{C}$ obtained a better absorption performance at $\mathrm{S}$ and $\mathrm{C}$ frequency band. However, at $\mathrm{X}$ band, Model D obtained better absorption performance than Model C. Finally at $60^{\circ}$, Model D obtained better absorption performance at the frequency band C-band while Model $\mathrm{C}$ obtained better absorption performance at X-band.

Overall, it is observed that apart from the variation of slot array designs and slot numbers, angles of measurement are also a crucial factor to determine the absorption performance of a pyramidal microwave absorber. These analysis results are very important to guide researchers in the study to improve the performance using slotted array technique or measurement angle.

\section{CONCLUSION}

In summary, the effects of measurement angle from incident wave and the application of slotted array technique on pyramidal microwave absorber for its absorption performance are presented. The absorption performance is observed to be very sensitive to different angles in the desired frequency range of $1-12 \mathrm{GHz}$. The sensitivity is also influenced by the variety of slot array designs applied to the absorber. It was also concluded that, there is a certain slot design that is suitable for certain angles of measurement that act as a potential combination to achieve better absorbing performance.

\section{ACKNOWLEDGEMENT}

The authors would want to specific the appreciation to Kementerian Pengajian Malaysia FRGS/1/2018/TK1 0/UITM/02/20 and all the events involved, mainly the Microwave Laboratory, UiTM Penang staff at some stage in the study were conducted.

\section{REFERENCES}

[1] H. Nornikman, F. Malek, P. J. Soh, and A. A. H. Azremi, "Effect on Source Signal Condition for Pyramidal Microwave Absorber Performance," in International Conference on Computer and Communication Engineering, 2010, no. May, pp. 11-13.

[2] F. Malek, Z. Liyana, and F. H. Wee, "Reflection Loss Performance of Double Pyramidal Microwave Absorber," in 1st IEEE International Symposium on Telecommunication Technologies Reflection, 2012, pp. 6-10.

[3] S. I. Orakwue and I. P. Onu, "Pyramidal Microwave Absorber Design for Anechoic Chamber in the Microwave Frequency Range of $1 \mathrm{GHz}$ to," Eur. J. Eng. Res. Sci., vol. 4, no. 10, pp. 8-10, 2019.
[4] M. K. M. Salleh, M. Yahya, Z. Awang, W. N. W. Muhamad, A. M. Mozi, and N. Yaacob, "Single layer coconut shell-based microwave absorbers," in IEEE Region 10 Annual International Conference, Proceedings/TENCON, 2011, pp. 1110-1113.

[5] I. M. Ibrahim, N. M. Yaakob, M. N. Husain, S. M. Se, A. Shaaban, P. Pos, and D. Tunggal, "The Effect of Carbon to the S11 on the Pyramidal Microwave Absorbers," 2011 IEEE Symp. Wirel. Technol. Appl., no. 3, pp. 141-145, 2011.

[6] B. S. Yew and F. H. Wee, "Agricultural Waste Based-Coco Peat Microwave Absorber," Int. J. Eng. Sci. Emerg. Technol., vol. 7, no. 2, pp. 547-554, 2014.

[7] H. Zhao, Y. Cheng, W. Liu, L. Yang, B. Zhang, L. P. Wang, G. Ji, and Z. J. Xu, "Biomass-Derived Porous Carbon-Based Nanostructures for Microwave Biomass $\square$ Derived Porous Carbon $\square$ Based Nanostructures for Microwave Absorption," in Nano-Micro Letters, 2019, no. April, pp. 2-18.

[8] H. Nornikman, P. J. Soh, A. A. H. Azremi, and M. S. Anuar, "Performance simulation of pyramidal and wedge microwave absorbers," in Proceedings - 2009 3 rd Asia International Conference on Modelling and Simulation, AMS 2009, 2009, pp. 649-654.

[9] L. Jiang, S. Yang, A. Wu, J. Liu, and H. Chen, "The matching design of electromagnetic parameters for obtaining excellent microwave- absorption properties by numerical simulation method," J. Electromagn. Waves Appl., vol. 5071, no. November, pp. 1-11, 2017.

[10] N. Hassan, H. A. Idris, M. F. Abd Malek, M. N. Taib, W. K. Wan Ali, S. P. Jack, A. A. Al-Hadi, and W. F. Hoon, "Measurement of pyramidal microwave absorbers using RCS methods," 2010 Int. Conf. Intell. Adv. Syst. ICIAS 2010, pp. 6-10, 2010.

[11] J. Zhang, P. Wang, G. Wang, B. Duan, T. Wang, and $\mathrm{F}$. Li, "Investigation on the absorption performance by separated electromagnetic waves reflected from different interfaces of absorber," J. Magn. Magn. Mater., vol. 498, no. October 2019, p. 166096, 2020.

[12] N. F. N. Yah, H. A. Rahim, Y. S. Lee, F. H. Wee, and H. H. Zainal, "Electromagnetic Wave Absorption Properties of Novel Green Composites Coconut Fiber Coir and Charcoal Powder over X-band Frequency for Electromagnetic Wave Absorbing Applications," Adv. Electromagn., vol. 7, no. 1, pp. 13-18, 2018.

[13] R. Ray, M. Pal, and A. K. Saha, "Investigation on Multiple Resonant Frequency and Size Reduction of Slot Loaded Square Patch Frequency Selective Surface," Int. J. Sci. Adv. Res. Technol., vol. 4, no. 1, pp. 25-27, 2018.

[14] A. Bendali, S. Bri, M. Habibi, M. N. Srifi, and A. El Fellahin, "Study and design a novel adaptive array antenna for a RFID applications," Int. J. Emerg. Trends Eng. Res., vol. 7, no. 12, pp. 805-811, 2019. 
Mas Izzati Fazin et al., International Journal of Emerging Trends in Engineering Research, 8(9), September 2020, 6306 - 6312

[15] H. A. El-Hakim, K. R. Mahmoud, and A. Abdelaziz, "Design of Compact Double-Layer Microwave Absorber for X-Ku Bands Using Genetic Algorithm," Prog. Electromagn. Res. B, vol. 65, no. January, pp. 157-168, 2016.

[16] K. Vamsi, I. Journal, K. V. Krishna, H. Khan, and K. K. Naik, "A Compact Rectangular Shaped Dipole Array Slot Microstrip Antenna with DGS for Multiband Applications," Int. J. Emerg. Trends Eng. Res., vol. 8, no. 2, 2020.

[17] A. Syahmi, H. Abdullah, R. Akhbar, N. R. Ahmad, N. S. Sazalee, A. R. Razali, and M. N. Taib, "Radiation Cross Section Characteristics for Isosceles Slotted Triangle on Hollow Pyramidal Absorber," 2018 IEEE Int. Conf. Autom. Control Intell. Syst., pp. 1-4, 1950.

[18] H. Abdullah@ Idris, M. N. Taib, M. S. I. Nazaruddin, N. R. Ahmad, A. Ahmad, N. A. Ismail, L. M. Kasim, N. M. Kasim, and N. M. Noor, "Slot Radial Array Design on Hollow Pyramidal Microwave Absorber," Appl. Mech. Mater., vol. 850, pp. 77-81, 2016.

[19] A. S. Yusof, H. Abdullah, N. R. A. A. Fauzi, N. A. Ismail, A. R. Razali, A. Ahmad, M. N. Taib, A. Azmin, N. M. Kasim, and A. M. Mozi, "Slotted triangle on hollow pyramidal microwave absorber characteristics," in Proceedings - 6th IEEE International Conference on Control System, Computing and Engineering, ICCSCE 2016, 2017, no. November, pp. 563-568.

[20] M. W. B. Silva and L. C. Kretly, "A new concept of RAM-Radiation Absorbent Material: Applying corrugated surfaces to improve reflectivity," in SBMO/IEEE MTT-S International Microwave and Optoelectronics Conference Proceedings, 2011, pp. 556-560.

[21] X. Chen, Z. Wu, Z. Zhang, and Y. Zou, "Ultra-broadband and wide-angle absorption based on 3D-printed pyramid," Opt. Laser Technol., vol. 124, no. November 2019, p. 105972, 2020.

[22] A. Don, M. Africa, I. Journal, A. D. M. Africa, L. R. Bulda, E. Del Rosario, M. Z. Marasigan, and I. Navarro, "Radio Wave Propagation: Simulation of Free Space Propagation Path Loss," Int. J. Emerg. Trends Eng. Res., vol. 8, no. 2, pp. 281-287, 2020.

[23] N. M. F. and M. N. T. N Mohamat Kasim, H Abdullah@Idris, M F A B Ali Mokhtar, A Ahmad, N Mohamad Noor, L Mohd Kasim, N A Ismail and Faculty, "Corrugated bamboo roofing design of microwave absorber for reflection absorption Corrugated bamboo roofing design of microwave absorber for reflection absorption," in Journal of Physics Conference Series, 2019, pp. 2-8. 